Check for updates

Cite this: RSC Adv., 2018, 8, 33516

Received 14th August 2018

Accepted 24th September 2018

DOI: $10.1039 / c 8 r a 06806 b$

rsc.li/rsc-advances

\section{Facile synthesis of novel porous self-assembling hydrogen-bonding covalent organic polymers and their applications towards fluoroquinolone antibiotics adsorption $\dagger$}

\begin{abstract}
Zhuoran Li, ${ }^{a}$ Feifan Xu, ${ }^{a}$ Zhi Liu, ${ }^{b}$ Chuanyu Qin, ${ }^{a}$ Hao Ren ${ }^{c}$ and Yangxue Li (iD *a
A series of porous hydrogen-bonding covalent organic polymers ( $\mathrm{H}_{\mathrm{C}} \mathrm{OPs}$ ) have been synthesized based on three-composite building blocks through a quick and succinct method for fluoroquinolone antibiotics adsorption from aqueous solutions. The porous properties of the $\mathrm{H}_{\mathrm{C}} \mathrm{OPs}$ were regulated and controlled by adjusting the lengths of linkers, and the crystallinity and stability were strengthened due to the introduction of hydrogen bonds in $\mathrm{H}_{\mathrm{C}} \mathrm{OPs}$. Taking advantage of the porous properties and $\pi$-conjugated phenyl rings, as well as functional $-\mathrm{CO}-\mathrm{NH}-$ and $-\mathrm{COOH}$ groups, $\mathrm{H}_{\mathrm{C}} \mathrm{OPs}$ removed organic pollutants from wastewater effectively and showed good reusability. The external adsorption behavior was analyzed using both kinetic analysis and isotherm analysis. The results showed that the adsorption obeys the pseudo-second order kinetic model and follows the Langmuir isotherm model. The obtained maximum adsorption capacity of the four $\mathrm{H}_{\mathrm{C}} \mathrm{OPs}$ was arranged in sequence according to the specific surface areas and pore sizes. Furthermore, the internal mechanisms involving perforated porousness, electrostatic interaction, hydrophobic interaction, $\pi-\pi$ electron-donor-acceptor (EDA) interaction and hydrogen bonding formation, were investigated in detail. We envisage broadly applying the $\mathrm{H}_{\mathrm{C}} \mathrm{OPs}$ in the facile and effective management of environmental pollution.
\end{abstract}

\section{Introduction}

Fluoroquinolones, used in pharmaceutical and personal care products (PPCPs), are synthetic antibiotics widely used in human medical and animal husbandry. ${ }^{1}$ With the improvement of human living standards, such antibiotics are extensively produced and used, and most of them tend to drain into the aquatic environment. Moreover, even a low concentration of antibiotics, will lead to the drug resistance of pathogenic bacteria and pose a serious threat to natural ecosystems and human health. In recent years, different degrees of such antibiotic pollution have been detected in various water environments. For example, in the United States, the concentrations of fluoroquinolone were detected to be 2 and $0.12 \mu \mathrm{g} \mathrm{L^{-1 }}$ in municipal wastewater and surface water, respectively; ${ }^{2}$ and in

\footnotetext{
${ }^{a}$ Key Lab of Groundwater Resources and Environment, Ministry of Education, Jilin University, 2519 Jiefang Road, Changchun 130021, P. R. China.E-mail: yangxueli@ jlu.edu.cn

${ }^{b}$ School of Municipal and Environmental Engineering, Jilin Jianzhu University, 5088 Xincheng Street, Changchun 130118, P. R. China

${ }^{c}$ State Key Laboratory of Inorganic Synthesis and Preparative Chemistry, College of Chemistry, Jilin University, Changchun 130012, P. R. China

$\dagger$ Electronic supplementary information (ESI) available: Fig. S1-S16, Table S1-S10 and additional experimental and characterization details. See DOI: 10.1039/c8ra06806b
}

the sewage from German hospitals, the concentration of fluoroquinolone was as high as $124.5 \mu \mathrm{g} \mathrm{L}{ }^{-1} \cdot{ }^{3} \mathrm{Xu}$ et al. investigated the average concentrations of fluoroquinolone in the main-

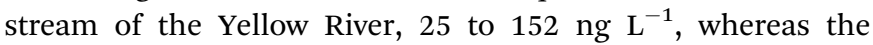
concentrations in the tributaries can reach up to 44 to $240 \mathrm{ng} \mathrm{L}{ }^{-1}$. $^{4}$ Therefore, it counts for a great deal to discuss the removal of fluoroquinolones from water. In many antibiotic wastewater treatment technologies, adsorption technology distinguishes itself from others with simple operation, little equipment investment cost and energy consumption, and no production of toxic intermediates. ${ }^{5}$ Considering the defective performance of existing adsorbents, developing new types of adsorbents comes to be burning issues in remediation of wastewater.

On the other hand, covalent organic polymers (COPs) consisted of covalent linkages, including both crystalline and amorphous forms, have been definitely showcased their striking charm across environment domains, healthcare sectors and energy-related fields. ${ }^{6}$ In general, the synthesis of COPs have been realized through employing finite one or two types of monomers to form limited linkages including B-O linkages, $\mathrm{C}-\mathrm{N}$ linkages, $\mathrm{C}-\mathrm{C}$ linkages, $\mathrm{N}-\mathrm{N}$ linkages, etc. for constructing 2D/3D motifs. ${ }^{7}$ Apparently, although the progress achieved to what it is today, the restricted species and structure-types of COPs associated with the monotonous building blocks and 
special bonding modes, making the unsatisfactory full pay of COP values. In this way, exploring novel COPs with multiple linkages and versatile structures is an unquestionable necessity rather than just an option to meet the requirements of promoting application. ${ }^{8}$

Alternatively, hydrogen-bonded organic frameworks (HOFs) which rely on weak interactions e.g., van der Waals force, hydrogen bonding, $\pi-\pi$ stacking and so forth, gradually emerge as a new highly innovative subject ever since first proposed by Chen's Group in 2011. ${ }^{9}$ However, the weaknesses of weak stability of HOFs outweigh the strengths of mild synthetic conditions. As a result, the practical applications of HOFs in environmental settings have been obstructed. Inspired by the pioneer work well established by Lin et al., a similar concept could be generated to develop hydrogen-bonded covalent organic polymers $\left(\mathrm{H}_{\mathrm{C}} \mathrm{OPs}\right)$, which would leverage merits of both COPs and HOFs. ${ }^{10}$

To evidence this assumption, a series of porous hydrogenbonding covalent organic polymers $\left(\mathrm{H}_{\mathrm{C}} \mathrm{OPs}\right)$ were obtained by self-assembly of multiple types of mixed linkers through catalyst-free dynamic imine chemistry and hydrogen bonding within an extremely short time (Scheme 1). The strategy for preparing novel $\mathrm{H}_{\mathrm{C}} \mathrm{OPs}$ was designed reasonably: (1) three types of monomers involving hydrazines, aldehydes and carboxylics were chosen as building blocks, bringing new features to the existing porous organic materials; (2) the $C_{3}$-symmetric benzene-1,3,5-tricarbohydrazide (BTCH) containing carbohydrazide functional groups, not only could form hydrogen bonds with carboxylic monomers, but also could construct hydrazone linkages with aldehyde monomers; (3) by adjusting the length of linear monomers providing great potential extensibility and diversity of packing patterns; and moreover, (4) the introduction of hydrogen bonding coupled with covalent bonds affording high chemical stability towards selective adsorbing environmental pollutants. Herein, the resulting $\mathrm{H}_{\mathrm{C}} \mathrm{OPs}$ were explored as a new type of adsorbents for two typical kinds of fluoroquinolone, i.e., ciprofloxacin (CIP) and norfloxacin (NOR) (Scheme 2). Notably, as far as we know, it was the first-time use of $\mathrm{H}_{\mathrm{C}} \mathrm{OPs}$ for adsorbing fluoroquinolone antibiotics to address the environmental issues.

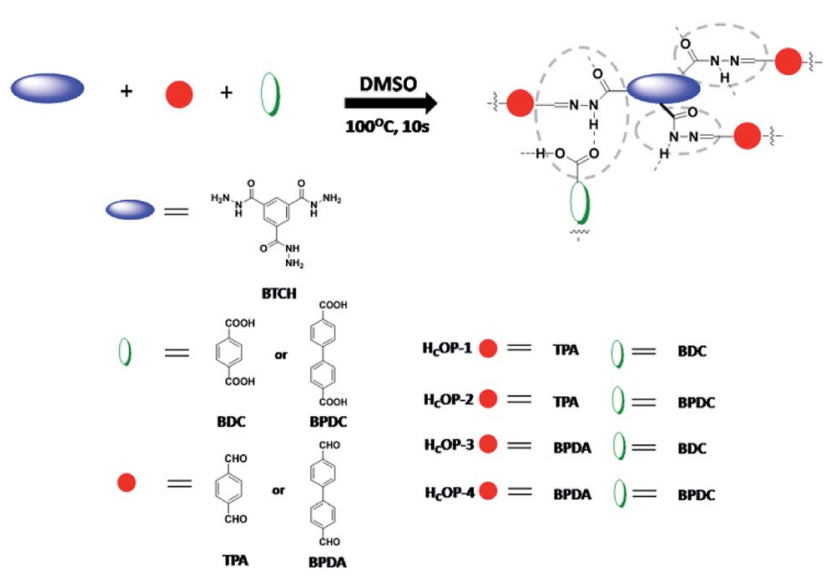

Scheme 1 Representative molecular structures of $\mathrm{H}_{\mathrm{C}} \mathrm{OPs}$.
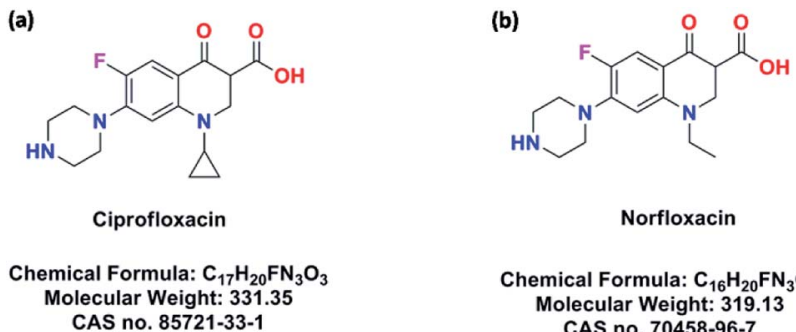

Chemical Formula: $\mathrm{C}_{16} \mathrm{H}_{20} \mathrm{FN}_{3} \mathrm{O}_{3}$ Molecular Weight: $\mathbf{3 1 9 . 1 3}$ CAS no. 70458-96-7

Scheme 2 Chemical information of ciprofloxacin (a) and norfloxacin (b).

\section{Experimental}

\section{Reagents and materials}

All starting reagents, except benzene-1,3,5-tricarbohydrazide, ${ }^{7 e}$ were purchased commercially and used directly as received without further purification.

\section{Characterization}

The thermogravimetric analyses (TGA) were performed by heating the $\mathrm{H}_{\mathrm{C}} \mathrm{OPs}$ at a heating rate of $10^{\circ} \mathrm{C} \mathrm{min}^{-1}$ in $\mathrm{N}_{2}$ flow. CHN elemental chemical analyses of the $\mathrm{H}_{\mathrm{C}} \mathrm{OPs}$ were carried out by an Elementar model Vario Micro analyzer. The fourier transform infrared spectra (FT-IR) of the $\mathrm{H}_{\mathrm{C}} \mathrm{OPs}$ were recorded by using a Nicolet Impact 410 Fourier transform infrared spectrometer through a $\mathrm{KBr}$ disc method in a range of $400-$ $4000 \mathrm{~cm}^{-1}$. The surface areas and porosities of the $\mathrm{H}_{\mathrm{C}} \mathrm{OPs}$ were measured on a Micromeritics ASAP 2020 analyzer. The powder $\mathrm{X}$-ray diffraction (PXRD) patterns of the $\mathrm{H}_{\mathrm{C}} \mathrm{OPs}$ were conducted by a Riguku D/MAX2550 diffractometer using $\mathrm{CuK} \alpha$ radiation with a wavelength of $1.54178 \AA$. The morphologies and structures of the $\mathrm{H}_{\mathrm{C}} \mathrm{OPs}$ were probed by field-scanning electron microscopy (FE-SEM, JEOLJXA-840, $15 \mathrm{kV}$ ) and the solid-state ${ }^{13} \mathrm{C}$ cross-polarization/magic-angle spinning nuclear magnetic resonance (CP/MAS NMR, Bruker AVANCE III NMR spectrometer, $400 \mathrm{MHz}$ ). The UV-vis diffuse reflectance of the $\mathrm{H}_{\mathrm{C}} \mathrm{OPs}$ spectra were recorded by a UV-vis spectrophotometer (UV-2550, Shimadzu) at room temperature. Point zero charge of the $\mathrm{H}_{\mathrm{C}} \mathrm{OPs}$ were measured at various $\mathrm{pH}$ with a JS94H (Shanghai, China).

\section{Synthesis of $\mathrm{H}_{\mathrm{C}} \mathrm{OP}-1$}

A mixture of benzene-1,3,5-tricarbohydrazide (BTCH, $0.2 \mathrm{mmol}$, $0.05 \mathrm{~g}$ ), terephthalaldehyde (TPA, $0.3 \mathrm{mmol}, 0.04 \mathrm{~g}$ ) and terephthalic acid (BDC, $0.3 \mathrm{mmol}, 0.05 \mathrm{~g}$ ) in dimethyl sulphoxide (DMSO, $10 \mathrm{~mL}$ ) was stirred and heated at $100{ }^{\circ} \mathrm{C}$ for about $10 \mathrm{~s}$. After that, the resulting yellow polymer $\left(\mathrm{H}_{\mathrm{C}} \mathrm{OP}-1\right)$ could be achieved with $94 \%$ yield. Elemental analysis (wt\%) calcd. For $\left\{\mathrm{C}_{28} \mathrm{H}_{21} \mathrm{~N}_{6} \mathrm{O}_{7}\right\}_{n}$ : C 60.76, H 3.82, N 15.18; found: C 60.55, H 3.97, N 15.74 .

\section{Synthesis of $\mathrm{H}_{\mathrm{C}} \mathrm{OP}-2$}

A mixture of benzene-1,3,5-tricarbohydrazide (BTCH, $0.2 \mathrm{mmol}$, $0.05 \mathrm{~g}$ ), terephthalaldehyde (TPA, $0.3 \mathrm{mmol}, 0.04 \mathrm{~g}$ ) and 
biphenyl-4,4'-dicarboxylic acid (BPDC, $0.3 \mathrm{mmol}, 0.07 \mathrm{~g}$ ) in dimethyl sulphoxide (DMSO, $10 \mathrm{~mL}$ ) was stirred and heated at $100{ }^{\circ} \mathrm{C}$ for about $10 \mathrm{~s}$. After that, the resulting yellow polymer $\left(\mathrm{H}_{\mathrm{C}} \mathrm{OP}-2\right)$ could be achieved with $95 \%$ yield. Elemental analysis (wt\%) calcd. For $\left\{\mathrm{C}_{34} \mathrm{H}_{25} \mathrm{~N}_{6} \mathrm{O}_{7}\right\}_{n}$ : C 64.86, H 4.00, N 13.35; found: C 64.55, H 4.16, N 13.74 .

\section{Synthesis of $\mathrm{H}_{\mathrm{C}} \mathrm{OP}-3$}

A mixture of benzene-1,3,5-tricarbohydrazide (BTCH, $0.2 \mathrm{mmol}$, $0.05 \mathrm{~g}$ ), 4,4'-biphenyldicarboxaldehyde (BPDA, $0.3 \mathrm{mmol}, 0.06 \mathrm{~g}$ ) and terephthalic acid (BDC, $0.3 \mathrm{mmol}, 0.05 \mathrm{~g}$ ) in dimethyl sulphoxide (DMSO, $10 \mathrm{~mL}$ ) was stirred and heated at $100^{\circ} \mathrm{C}$ for about $10 \mathrm{~s}$. After that, the resulting yellow polymer $\left(\mathrm{H}_{\mathrm{C}} \mathrm{OP}-3\right)$ could be achieved with $90 \%$ yield. Elemental analysis (wt\%) calcd. For $\left\{\mathrm{C}_{34} \mathrm{H}_{25} \mathrm{~N}_{6} \mathrm{O}_{7}\right\}_{n}$ : C 64.86, H 4.00, N 13.35; found: $\mathrm{C}$ 64.85, H 4.07, N 13.39.

\section{Synthesis of $\mathrm{H}_{\mathrm{C}} \mathrm{OP}-4$}

A mixture of benzene-1,3,5-tricarbohydrazide (BTCH, $0.2 \mathrm{mmol}$, $0.05 \mathrm{~g}$ ), 4,4'-biphenyldicarboxaldehyde (BPDA, $0.3 \mathrm{mmol}, 0.06 \mathrm{~g}$ ) and biphenyl-4,4'-dicarboxylic acid (BPDC, $0.3 \mathrm{mmol}, 0.07 \mathrm{~g}$ ) in dimethyl sulphoxide (DMSO, $10 \mathrm{~mL}$ ) was stirred and heated at $100{ }^{\circ} \mathrm{C}$ for about $10 \mathrm{~s}$. After that, the resulting yellow polymer $\left(\mathrm{H}_{\mathrm{C}} \mathrm{OP}-4\right)$ could be achieved with $92 \%$ yield. Elemental analysis (wt\%) calcd. For $\left\{\mathrm{C}_{40} \mathrm{H}_{29} \mathrm{~N}_{6} \mathrm{O}_{7}\right\}_{n}$ : C 68.08, H 4.14, N 11.91; found: C 67.95, H 4.16, N 12.04.

\section{Adsorption experiments}

All adsorption experiments were carried out with batch experiments at ambient temperature in air. In a general procedure, $10 \mathrm{mg} \mathrm{H}_{\mathrm{C}} \mathrm{OPs}$ were added into $10 \mathrm{~mL}$ solution of fluoroquinolones $\left(2-20 \mathrm{mg} \mathrm{L}^{-1}\right)$. Thereafter, the mixture was stirred on a rotating shaker for a certain time at ambient temperature. Then the supernatant was measured by UV-vis spectrometry at wavelength of $277 \mathrm{~nm}$ for ciprofloxacin and $278 \mathrm{~nm}$ for norfloxacin at various time intervals to calculate the residue amount of fluoroquinolones in the solution.

\section{Results and discussion}

\section{Characterization of $\mathrm{H}_{\mathrm{C}} \mathrm{OPs}$}

Scanning electron microscopy (SEM) images showed that $\mathrm{H}_{\mathrm{C}} \mathrm{OP}$ 1 and $\mathrm{H}_{\mathrm{C}} \mathrm{OP}-2$ appeared nanoporous interconnected particles, while $\mathrm{H}_{\mathrm{C}} \mathrm{OP}-3$ and $\mathrm{H}_{\mathrm{C}} \mathrm{OP}-4$ exhibited uniform rectangular morphologies, respectively (Fig. 1a-d). The PXRD patterns of the $\mathrm{H}_{\mathrm{C}} \mathrm{OPs}$ were in line with the amorphous nature (Fig. S1, ESI $\dagger$ ). Interestingly, the sharp peaks were observed in $\mathrm{H}_{\mathrm{C}} \mathrm{OPs}$, corresponding to the hydrogen bonds which could strengthen the crystallinity. ${ }^{11 a}$ The stability of $\mathrm{H}_{\mathrm{C}} \mathrm{OPs}$ was studied in the presence of concentrated $\mathrm{HCl}$. To our surprise, the $\mathrm{H}_{\mathrm{C}} \mathrm{OPs}$ didn't dissolve and the PXRD patterns changed little even after 3 days (Fig. S2, ESI $\dagger$ ). As we know, the hydrazone linkage is dynamic and acid-sensitive, we suggest that the high stability of $\mathrm{H}_{\mathrm{C}} \mathrm{OPs}$ possibly results from the hydrogen bonds formed between the BTCH moieties and BDC (or BPDC) moieties in $\mathrm{H}_{\mathrm{C}} \mathrm{OPs} .{ }^{11 b}$

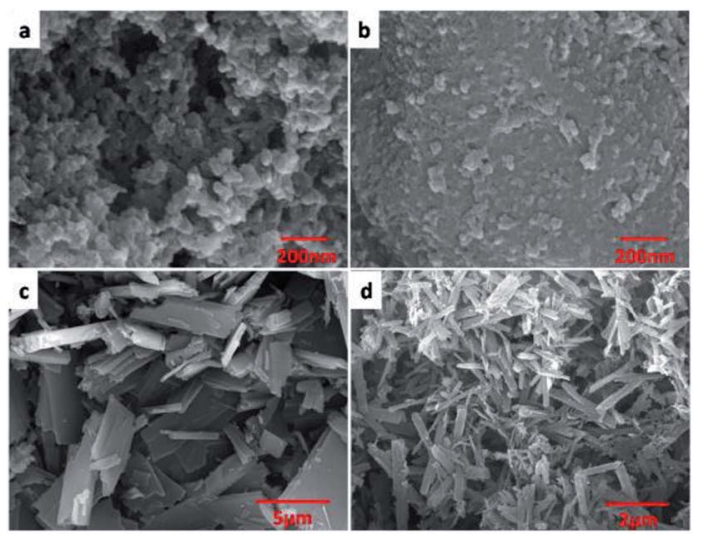

Fig. 1 SEM images of $\mathrm{H}_{C} \mathrm{OP}-1$ (a), $\mathrm{H}_{C} \mathrm{OP}-2$ (b), $\mathrm{H}_{C} \mathrm{OP}-3$ (c) and $\mathrm{H}_{C} \mathrm{OP}-$ 4 (d).

The FT-IR spectra of $\mathrm{H}_{\mathrm{C}} \mathrm{OPs}$ showed stretching peaks at $1288 \mathrm{~cm}^{-1}$ that are characteristic of $\mathrm{C}=\mathrm{N}$ moieties, implying the occurrence of aldehyde-hydrazine condensation reaction in the $\mathrm{H}_{\mathrm{C}} \mathrm{OPs}$ (Fig. S3 and S4, ESI $\dagger$ ). Furthermore, when comparing the FT-IR spectra of $\mathrm{H}_{\mathrm{C}} \mathrm{OPs}$ to monomers, we found that the stretching vibration of $\mathrm{N}-\mathrm{H}$ at $3300 \mathrm{~cm}^{-1}$ in $\mathrm{BTCH}$ blue-shifted towards higher wavelength of $3450 \mathrm{~cm}^{-1}$; meanwhile, the $\mathrm{C}=\mathrm{O}$ stretching band in BDC (or BPDC) red-shifted from 1685 to $1680 \mathrm{~cm}^{-1}$. These shifts can be ascribed to hydrogen-bonding interactions between carbonyl and imide. ${ }^{12 a}$ The successful formation of hydrogen bonds and hydrazone bonds in $\mathrm{H}_{\mathrm{C}} \mathrm{OPs}$ were also proved by the ${ }^{13} \mathrm{C} \mathrm{CP} / \mathrm{MAS} \mathrm{NMR}$ analysis at the molecular level. As shown in Fig. 2, the characteristic resonances at $170 \mathrm{ppm}$ and $160 \mathrm{ppm}$ of $\mathrm{C}=\mathrm{O}$ bonds provided the solid evidence for the presence of BDC (or BPDC) and BTCH, respectively. Meantime, the characteristic resonances at 145 ppm of $\mathrm{C}=\mathrm{N}$ bonds, proving the successful condensation of TPA (or BPDA) and BTCH again. ${ }^{12 b}$

The $\mathrm{H}_{\mathrm{C}} \mathrm{OP}-1$ and $\mathrm{H}_{\mathrm{C}} \mathrm{OP}-2$ are stable in $\mathrm{N}_{2}$ up to $300{ }^{\circ} \mathrm{C}$, while the $\mathrm{H}_{\mathrm{C}} \mathrm{OP}-3$ and $\mathrm{H}_{\mathrm{C}} \mathrm{OP}-4$ are stable in $\mathrm{N}_{2}$ up to $350{ }^{\circ} \mathrm{C}$, respectively, as revealed by TGA (Fig. S5, ESI $\dagger$ ). The porous structures of the $\mathrm{H}_{\mathrm{C}} \mathrm{OPs}$ were investigated by nitrogen sorption

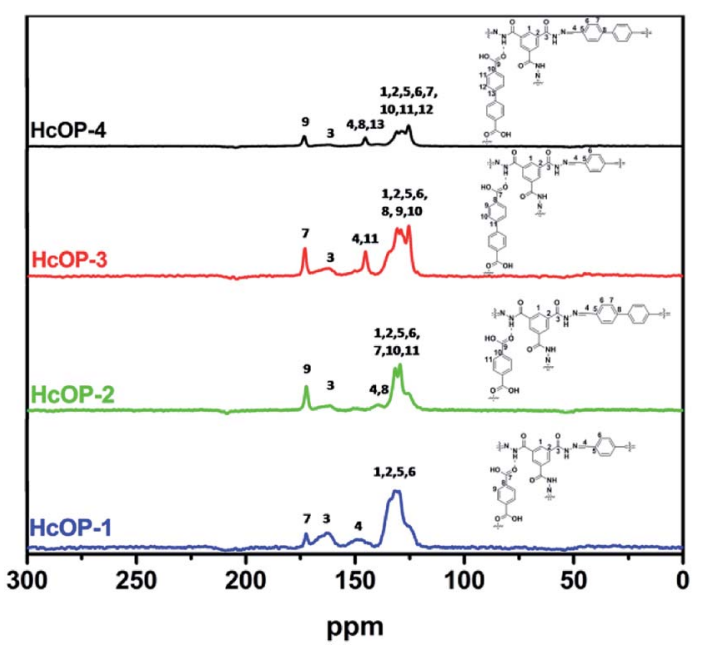

Fig. 2 Solid-state ${ }^{13} \mathrm{C} C P / M A S ~ N M R$ spectra of $\mathrm{H}_{\mathrm{C}} \mathrm{OPs}$. 
measurements at $77 \mathrm{~K} .{ }^{13}$ In light of the IUPAC classification, the $\mathrm{H}_{\mathrm{C}} \mathrm{OPs}$ all exhibited type IV sorption isotherm curves (Fig. S6 and S7, ESI $\dagger$ ). Among the four $\mathrm{H}_{\mathrm{C}} \mathrm{OPs}, \mathrm{H}_{\mathrm{C}} \mathrm{OP}-4$ displayed the relatively highest $\mathrm{N}_{2}$ uptake with a BET surface area of $43 \mathrm{~m}^{2} \mathrm{~g}^{-1}$ (Table $\mathrm{S} 1, \mathrm{ESI} \dagger$ ). And the remaining $\mathrm{H}_{\mathrm{C}} \mathrm{OPs}$ were arranged in descending order by the surface areas: $\mathrm{H}_{\mathrm{C}} \mathrm{OP}-3\left(41 \mathrm{~m}^{2} \mathrm{~g}^{-1}\right)>$ $\mathrm{H}_{\mathrm{C}} \mathrm{OP}-2\left(18 \mathrm{~m}^{2} \mathrm{~g}^{-1}\right)>\mathrm{H}_{\mathrm{C}} \mathrm{OP}-1\left(13 \mathrm{~m}^{2} \mathrm{~g}^{-1}\right)$. The BrunauerEmmett-Teller (BET) surface areas of $\mathrm{H}_{\mathrm{C}} \mathrm{OPs}$ increased along with increasing length of linkers, briefly, the surface areas are proportional to the length of linkers under the reaction conditions used. This finding is in accordance with the previous PTPA network. ${ }^{14}$

\section{Adsorption properties}

Adsorption amounts of ciprofloxacin and norfloxacin onto four $\mathrm{H}_{\mathrm{C}} \mathrm{OPs}$ at different $\mathrm{pH}$ values were depicted in Fig. $3 \mathrm{a}$ and b. It can be seen that the equilibrium adsorption capacities $\left(q_{\mathrm{e}}\right)$ of ciprofloxacin and norfloxacin both showed the increasing tendency and then decreasing tendency with $\mathrm{pH}$ values varied from 2 to 10 . This may be related to the various zeta potential values of $\mathrm{H}_{\mathrm{C}} \mathrm{OPs}$ and the different species of ciprofloxacin $\left(K_{\mathrm{a} 1}=\right.$ 6.1, $\left.K_{\mathrm{a} 2}=8.7\right)$ and norfloxacin $\left(K_{\mathrm{a} 1}=6.2, K_{\mathrm{a} 2}=8.5\right)$ changing with $\mathrm{pH}$, to be specific, cationic species $(\mathrm{pH}<5.9 \pm 0.15)$, zwitterionic species $(6.1<\mathrm{pH}<8.9)$ and anionic species $(\mathrm{pH}>$ $8.9 \pm 0.11) .{ }^{15}$ Typically, ciprofloxacin and norfloxacin contain
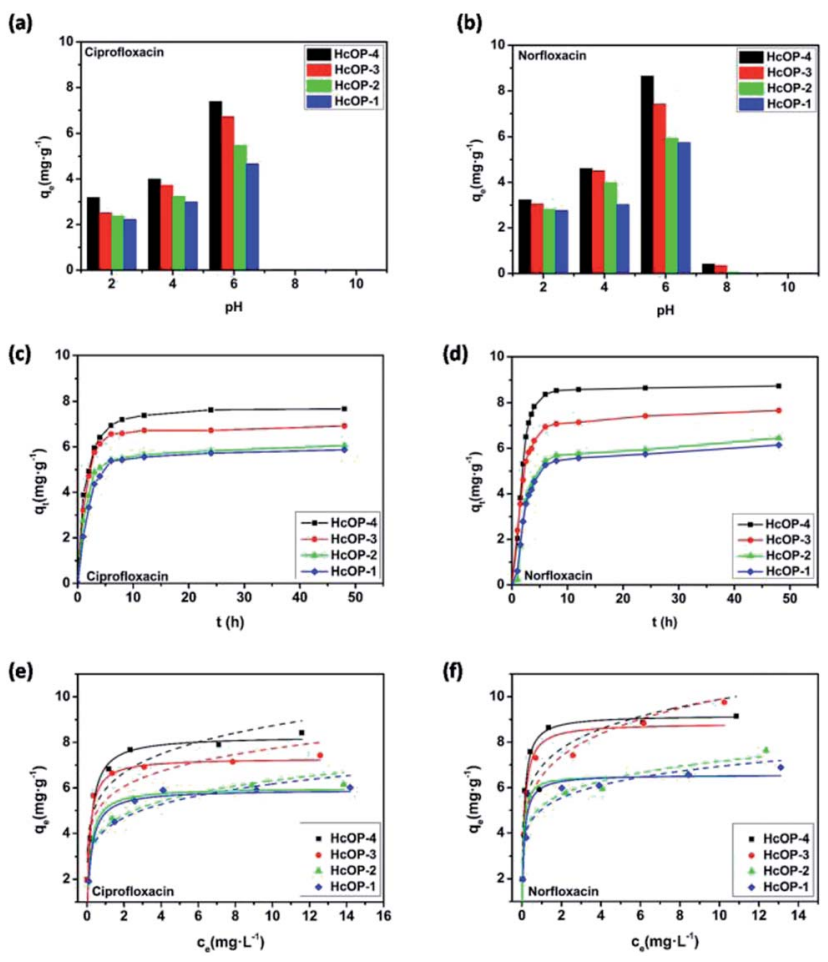

Fig. 3 (a) and (b) Effect of solution $\mathrm{pH}$ on antibiotics adsorption onto $\mathrm{H}_{\mathrm{C}} \mathrm{OPs}$. (c) and (d) the fluoroquinolone adsorption capacity under different contact times $\left(C_{0}=10 \mathrm{mg} \mathrm{L}^{-1}, \mathrm{pH}=6.0\right)$. (e) and (f) Langmuir and Freundlich adsorption isotherms of fluoroquinolones adsorption onto $\mathrm{H}_{\mathrm{C}} \mathrm{OPs}$. Dashed line: Freundlich model; solid line: Langmuir model. both $\mathrm{N}-\mathrm{H}$ and $-\mathrm{COOH}$ groups, which can be combined with the $\mathrm{H}^{+}$and $\mathrm{OH}^{-}$in the solution, thus affecting the fluoroquinolones adsorption onto $\mathrm{H}_{\mathrm{C}} \mathrm{OPs}$ (Fig. 4). Therefore, the changing of $\mathrm{pH}$ induced the mutual transformation of the electrostatic interactions and electrostatic repulsive force between fluoroquinolone molecules and the $\mathrm{H}_{\mathrm{C}} \mathrm{OP}$ surfaces, giving rise to the emergence of the maximum adsorption amounts at $\mathrm{pH}=$ 6.0. Accordingly, the optimal $\mathrm{pH}$ for the four $\mathrm{H}_{\mathrm{C}} \mathrm{OPs}$ over the two kinds of fluoroquinolones was pitched on $\mathrm{pH}=6.0$, which was for studying go a step further.

For the sake of investigating the behaviour of fluoroquinolones onto the $\mathrm{H}_{\mathrm{C}} \mathrm{OPs}$, batch adsorption experiments were conducted at different reaction times for the initial concentration of $10 \mathrm{mg} \mathrm{L^{-1 }}(\mathrm{pH}=6.0)$. As shown in Fig. $3 \mathrm{c}$ and $\mathrm{d}$, the adsorption processes of ciprofloxacin and norfloxacin on $\mathrm{H}_{\mathrm{C}} \mathrm{OPs}$ were rapid at the initial adsorption stage of $6 \mathrm{~h}$, after which the adsorption rate no longer changed and eventually entered the adsorption equilibrium process. The adsorption data of the $\mathrm{H}_{\mathrm{C}} \mathrm{OPs}$ over fluoroquinolones were processed by pseudo first- and second-order kinetic models, intraparticle diffusion model (Fig. S10, ESI $\dagger$ ). ${ }^{16}$ Owing to the higher linear fitting coefficient $\left(R^{2}\right)$ values and closer calculated equilibrium adsorption capacity $\left(q_{\mathrm{e}}, \mathrm{cal}\right)$ values of the two kinetic models, the second-order kinetic model described the nature of adsorption process more suitably (Tables S2 and S4, ESI $\dagger$ ). Moreover, the linear relationship between the $q_{t}$ and $t 0.5$ indicated the combined process of intraparticle diffusion and the external mass transfer in adsorption processes of fluoroquinolones onto the $\mathrm{H}_{\mathrm{C}}$ OPs being studied (Tables $\mathrm{S} 3$ and S5, ESI $\dagger$ ). For the adsorbed rates of antibiotics, the orders are in following

(a)

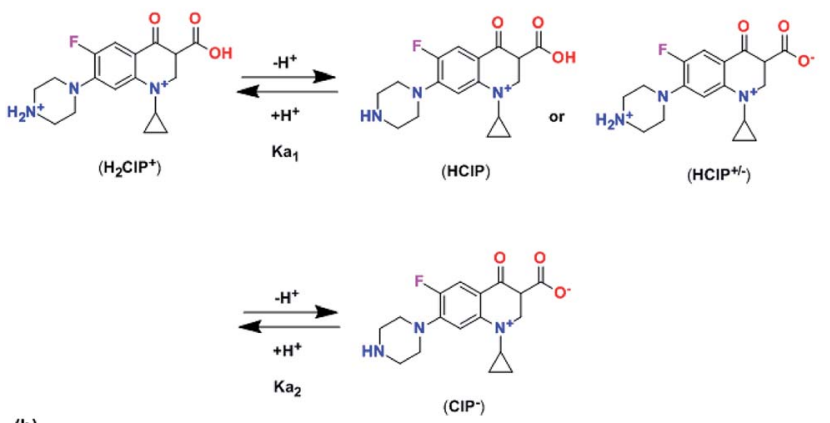

(b)
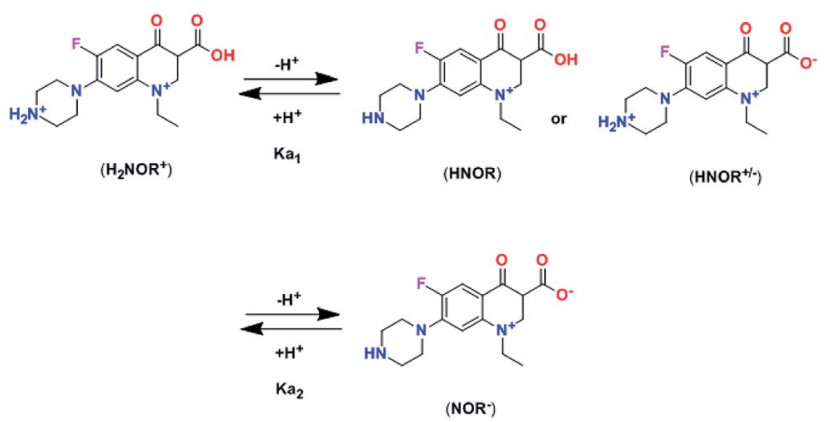

Fig. 4 The speciation of process reactive for ciprofloxacin (a) and norfloxacin (b) in aqueous solution as a function of the solution $\mathrm{pH}$. 
sequence of $\mathrm{H}_{\mathrm{C}} \mathrm{OP}-1<\mathrm{H}_{\mathrm{C}} \mathrm{OP}-2<\mathrm{H}_{\mathrm{C}} \mathrm{OP}-3<\mathrm{H}_{\mathrm{C}} \mathrm{OP}-4$, which can be contributed to the differences in specific surface areas and pore sizes. ${ }^{17}$ Besides, the removal efficiencies $(E)$ of fluoroquinolones onto the same kind of $\mathrm{H}_{\mathrm{C}} \mathrm{OPs}$ increased as $E_{\text {ciprofloxacin }}<$ $E_{\text {norfloxacin }}$, which is related to the hydrophobic interactions between the adsorbent and adsorbate.

In order to evaluate the adsorption capacities of fluoroquinolones onto the $\mathrm{H}_{\mathrm{C}} \mathrm{OPs}$, the adsorption amounts were tested as a function of various initial antibiotic concentrations (Fig. 3e and f). Both the Freundlich and Langmuir models were performed to fit test data (Fig. S11, ESI $\dagger$ ). ${ }^{18}$ By comparing the linear fitting coefficient $\left(R^{2}\right)$ values of both ciprofloxacin and norfloxacin, we can draw a conclusion that the adsorption process was interpreted reasonably well by the Langmuir isotherm model (Tables S6-S9, ESI $\dagger$ ). Based on the data listed, the maximum adsorption capacity $\left(q_{\mathrm{m}}\right)$ values calculated from the Langmuir model of four $\mathrm{H}_{\mathrm{C}} \mathrm{OPs}$ over two fluoroquinolones were both in the order of $\mathrm{H}_{\mathrm{C}} \mathrm{OP}-4>\mathrm{H}_{\mathrm{C}} \mathrm{OP}-3>\mathrm{H}_{\mathrm{C}} \mathrm{OP}-2>\mathrm{H}_{\mathrm{C}} \mathrm{OP}-1$, which impelled us to believe that the more favorable adsorption over $\mathrm{H}_{\mathrm{C}} \mathrm{OP}-4$ than the adsorption over $\mathrm{H}_{\mathrm{C}} \mathrm{OP}-3, \mathrm{H}_{\mathrm{C}} \mathrm{OP}-2$ or $\mathrm{H}_{\mathrm{C}} \mathrm{OP}-1$. This phenomenon is commonly observed in the adsorption process of porous materials, there, greater specific surface area appear to favour the higher adsorption capacity. ${ }^{\mathbf{1 9}}$ The other side, the $q_{\mathrm{m}}$ values of norfloxacin were larger than that of ciprofloxacin when using the same $\mathrm{H}_{\mathrm{C}} \mathrm{OP}$ as adsorbent. It is worth noting that with the values, $\mathrm{H}_{\mathrm{C}} \mathrm{OPs}$ could exceed some commercial materials and even some synthetic zeolites, providing the great feasibility as a popular alternative of existing adsorbents which avoids complex synthesis (Table S10†). Afterwards, the morphologies and structures of the $\mathrm{H}_{\mathrm{C}} \mathrm{OPs}$ after adsorption were characterized by SEM images and FT-IR analysis in succession. As shown in Fig. S12-16, $\uparrow$ the morphologies and structures of fluoroquinolone-loaded networks did not change significantly with regard to the parent networks, which further elaborated on the stability of $\mathrm{H}_{\mathrm{C}} \mathrm{OPs}$.

Since the sodium chloride commonly existed in the most wastewater, the influence of ionic strength $(\mathrm{NaCl})$ on fluoroquinolones adsorption onto cross-sectional $\mathrm{H}_{\mathrm{C}} \mathrm{OP}-4$ was carried out. As shown in Fig. 5a, the decreased adsorption amounts under low $\mathrm{NaCl}$ conditions (0 to $0.2 \mathrm{M}$ ) may be explained by the competitive adsorption of $\mathrm{Na}^{+}$cations with positive fluoroquinolones on the $\mathrm{H}_{\mathrm{C}} \mathrm{OP}-4$ surface. However, when ionic strength is large enough, the salting out effect between fluoroquinolone molecules and $\mathrm{NaCl}$, which leading to
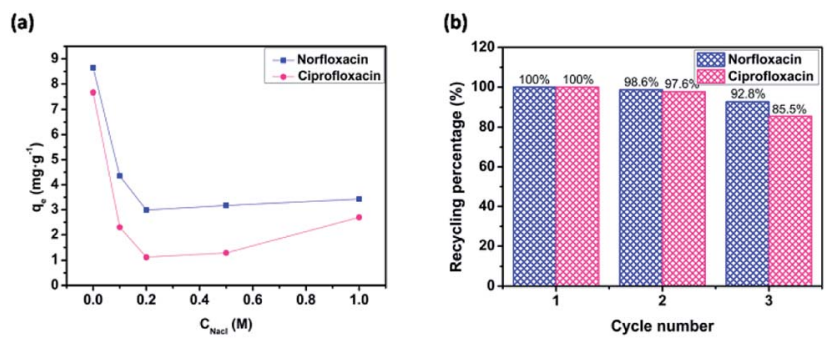

Fig. 5 (a) Effect of coexisting ions on adsorption capacity of fluoroquinolones onto $\mathrm{H}_{\mathrm{C}} \mathrm{OPs}$ at $\mathrm{pH}=6.0$. (b) Relative adsorption capacity of fluoroquinolones onto $\mathrm{H}_{C} \mathrm{OPs}$ after recycling. the decreased solubility of fluoroquinolone molecules in aqueous solution, resulting in the enhanced hydrophobic interactions between fluoroquinolones and $\mathrm{H}_{\mathrm{C}} \mathrm{OP}-4$. Therefore, more fluoroquinolones were facilitated to diffuse the surface of the $\mathrm{H}_{\mathrm{C}} \mathrm{OP}-4$, bringing about the increased adsorption amounts of fluoroquinolones under high initial $\mathrm{NaCl}$ concentrations $(0.5$ to $1 \mathrm{M}){ }^{20}$

The recyclability of the $\mathrm{H}_{\mathrm{C}} \mathrm{OP}$ adsorbents towards fluoroquinolones were investigated by using generated adsorbents for the subsequent adsorption cycles under the same conditions to explore the practical value. Similarly, $\mathrm{H}_{\mathrm{C}} \mathrm{OP}-4$ was selected as representative adsorbent for detailed investigation. The results in Fig. $5 \mathrm{~b}$ demonstrated that the recycling percentage of norfloxacin still maintained $92.8 \%$ (while $85.5 \%$ for that of ciprofloxacin) of the initial capacity after three recycles, defining the good repeatable application of $\mathrm{H}_{\mathrm{C}} \mathrm{OPs}$ in treatment of fluoroquinolones pollution.

\section{Adsorption mechanism}

To get a deep understanding of the mechanisms of adsorption for fluoroquinolones onto the four $\mathrm{H}_{\mathrm{C}} \mathrm{OPs}$, we speculated that it may be attributed to a combination of perforated porousness, electrostatic interaction, hydrophobic interaction, $\pi-\pi$ electron-donor-acceptor (EDA) interaction and hydrogen bonding formation (Fig. 6). ${ }^{21}$ Remarkably, the perforated porousness assumed enormous importance in the adsorption progress as discussed before that the large specific surface area is propitious to high adsorption capacity. The electrostatic interaction was without question one of the major effecting factors for antibiotics adsorption onto the $\mathrm{H}_{\mathrm{C}} \mathrm{OPs}$. We are informed of the zeta potential curves that when the $\mathrm{pH}$ was at 6.0, the surfaces of all the $\mathrm{H}_{\mathrm{C}} \mathrm{OPs}$ were negatively charged (Fig. S8, ESI $\dagger$ ); in contrast, the norfloxacin and ciprofloxacin can exist as cationic forms with positive charge. On these grounds, adsorption amounts were enhanced as expected due to the electrostatic attraction force between antibiotic molecules and the $\mathrm{H}_{\mathrm{C}} \mathrm{OPs}$ surfaces. Additionally, in terms of higher $E$ and $q_{\mathrm{m}}$ values for

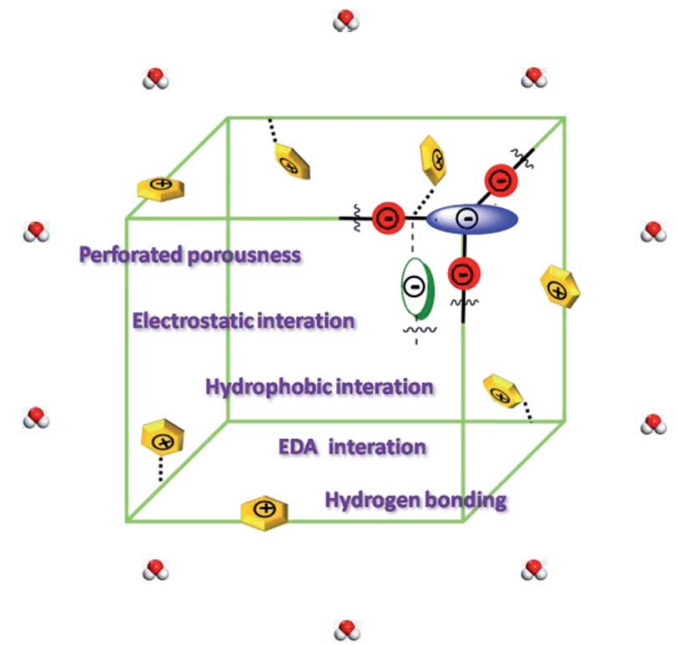

Fig. 6 Schematic diagram of possible mechanisms for adsorptive removal of fluoroquinolones. 
norfloxacin in comparison with ciprofloxacin onto $\mathrm{H}_{\mathrm{C}} \mathrm{OPs}$, the dominated role of hydrophobicity in fluoroquinolone adsorption has been fully given weight. Now that norfloxacin and ciprofloxacin could function as $\pi$-acceptors on account of electron-withdrawing -F groups; conversely, - $\mathrm{CO}-\mathrm{NH}-$ functional groups endow the $\mathrm{H}_{\mathrm{C}} \mathrm{OPs}$ with $\pi$-electron-rich skeletons, which could function as $\pi$-donors, the $\pi-\pi$ EDA interaction are prone to effect significantly in the fluoroquinolones adsorption onto the $\mathrm{H}_{\mathrm{C}} \mathrm{OPs}$. Last, hydrogen bond information also has a certain impact on the fluoroquinolones adsorption onto the $\mathrm{H}_{\mathrm{C}} \mathrm{OPs}$. The - $\mathrm{CO}-\mathrm{NH}-$ and - $\mathrm{COOH}$ functional groups on $\mathrm{H}_{\mathrm{C}} \mathrm{OPs}$ make them could act as hydrogen bond-donors as well as hydrogen bond-acceptors; correspondingly, the norfloxacin and ciprofloxacin could act as both hydrogen bond-acceptors and hydrogen bond-donors due to the $-\mathrm{NH},-\mathrm{COOH}$ and $-\mathrm{F}$ functional groups.

\section{Conclusions}

In conclusion, four novel porous hydrogen-bonding covalent organic polymers $\left(\mathrm{H}_{\mathrm{C}} \mathrm{OPs}\right)$ have been developed based on threecomposite building blocks as carriers to adsorb emerging fluoroquinolone pollutants via a facile method for the first time. The specific surface areas and pore sizes of these porous $\mathrm{H}_{\mathrm{C}} \mathrm{OPs}$, which bringing about the diverse in adsorption capacity, could be regulated to a certain extent by varying the lengths of strut. Or rather, the other three $\mathrm{H}_{\mathrm{C}} \mathrm{OPs}$ exhibited comparably low adsorption capacity in contrast to $\mathrm{H}_{\mathrm{C}} \mathrm{OP}-4$, which is a result that the absorbing abilities adhere to the order of porous characteristics. In the meantime, the functional groups on the skeletons of $\mathrm{H}_{\mathrm{C}} \mathrm{OPs}$, such as $-\mathrm{CO}-\mathrm{NH}-$ and $-\mathrm{COOH}$ groups, favored the adsorption of fluoroquinolones. In addition, it can be inferred that other possible controlling mechanisms such as electrostatic interaction, hydrophobic interaction, $\pi-\pi$ electron-donor-acceptor (EDA) interaction and hydrogen bonding formation also accompanied with effect on the fluoroquinolones adsorption onto $\mathrm{H}_{\mathrm{C}} \mathrm{OPs}$.

\section{Conflicts of interest}

There are no conflicts to declare.

\section{Acknowledgements}

This work was supported by the National Natural Science Foundation of China (Project No. 21601177, 41572213 and 41772241) and the 111 Project (B16020).

\section{Notes and references}

1 F. Pomati, S. Castiglioni, E. Zuccato, R. Fanelli, D. Vigetti, C. Rossetti and D. Calamari, Environ. Sci. Technol., 2006, 40, 2442-2447.

2 K. G. Karthikeyan and M. T. Meyer, Sci. Total Environ., 2006, 361, 196-207.
3 A. Hartmann, E. M. Golet, S. Gartiser, A. C. Alder, T. Koller and R. M. Widmer, Arch. Environ. Contam. Toxicol., 1999, 36, 115-119.

4 W. H. Xu, G. Zhang, S. C. Zou, Z. H. Ling, G. L. Wang and W. Yan, Water Environ. Res., 2009, 81, 248-254.

5 Z. J. Liang, Z. W. Zhao, T. Y. Sun, W. X. Shi and F. Y. Cui, J. Hazard. Mater., 2016, 305, 8-14.

6 (a) J. L. Segura, M. J. Mancheno and F. Zamora, Chem. Soc. Rev., 2016, 45, 5635-5671; (b) A. P. Côte, A. I. Benin, N. W. Ockwig, M. O'Keeffe, A. J. Matzger and O. M. Yaghi, Science, 2005, 310, 1166-1170; (c) X. Han, Q. Xia, J. Huang, Y. Liu, C. Tan and Y. Cui, J. Am. Chem. Soc., 2017, 139, 8693-8697; (d) B. Sun, C. H. Zhu, Y. Liu, C. Wang, L. J. Wan and D. Wang, Chem. Mater., 2017, 29, 4367-4374; (e) W. J. Luo, Y. X. Zhu, J. Y. Zhang, J. J. He, Z. G. Chi, P. W. Miller, L. P. Chen and C. Y. Su, Chem. Commun., 2014, 50, 11942-11945; (f) L. Guo, M. Wang, X. F. Zeng and D. P. Cao, Mater. Chem. Front., 2017, 1, 2643-2650; $(g)$ Q. Sun, B. Aguila and S. Q. Ma, Mater. Chem. Front., 2017, 1, 1310-1316; (h) H. S. Yang, Y. L. Zhu, Y. Du, D. Z. Tan, Y. H. Jin and W. Zhang, Mater. Chem. Front., 2017, 1, 13691372.

7 (a) M. Calik, T. Sick, M. Dogru, M. Döblinger, S. Datz, H. Budde, A. Hartschuh, F. Auras and T. Bein, J. Am. Chem. Soc., 2016, 138, 1234-1239; (b) D. A. Vazquez-Molina, G. M. Pope, A. A. Ezazi, J. L. Mendoza-Cortes, J. K. Harper and F. J. Uribe-Romo, Chem. Commun., 2018, 54, 69476950; (c) Y. C. Yuan, B. Sun, A. M. Cao, D. Wang and L. J. Wan, Chem. Commun., 2018, 54, 5976-5979; (d) F. Yuan, J. Tan and J. Guo, Sci. China: Chem., 2018, 61, 143-152; (e) L. Lin, H. D. Guan, D. L. Zou, Z. J. Dong, Z. Liu, F. F. Xu, Z. G. Xie and Y. X. Li, RSC Adv., 2017, 7, 54407-54415.

8 S. Chandra, T. Kundu, K. Dey, M. Addicoat, T. Heine and R. Banerjee, Chem. Mater., 2016, 28, 1489-1494.

9 (a) Y. B. He, S. C. Xiang and B. L. Chen, J. Am. Chem. Soc., 2011, 133, 14570-14573; (b) Q. Yin, P. Zhao, R. J. Sa, G. C. Chen, J. Lü, T. F. Liu and R. Cao, Angew. Chem., Int. Ed., 2018, 57, 7691-7696; (c) Z. F. Ju, G. L. Liu, Y. S. Chen, D. Q. Yuan and B. L. Chen, Chem. - Eur. J., 2017, 23, 47744777; (d) W. Q. Yan, X. P. Yu, T. Yan, D. F. Wu, E. Ning, Y. Qi, Y. F. Han and Q. W. Li, Chem. Commun., 2017, 53, 3677-3680; (e) H. L. Wang, H. Wu, J. L. Kan, G. G. Chang, Z. Z. Yao, B. Li, W. Zhou, S. C. Xiang, J. C. G. Zhao and B. L. Chen, J. Mater. Chem. A, 2017, 5, 8292-8296; $(f)$ Y. Zhou, B. Liu, X. D. Sun, J. T. Li, G. H. Li, Q. S. Huo and Y. L. Liu, Cryst. Growth Des., 2017, 17, 6653-6659.

10 Y. X. Lin, X. F. Jiang, S. T. Kim, S. B. Alahakoon, X. S. Hou, Z. Y. Zhang, C. M. Thompson, R. A. Smaldone and C. F. Ke, J. Am. Chem. Soc., 2017, 139, 7172-7175.

11 (a) X. H. Guo, Y. Tian, M. C. Zhang, Y. Li, R. Wen, X. Li, X. F. Li, Y. Xue, L. J. Ma, C. Q. Xia and S. J. Li, Chem. Mater., 2018, 30, 2299-2308; (b) S. X. Duan, J. X. Li, X. Liu, Y. N. Wang, S. Y. Zeng, D. D. Shao and T. Hayat, ACS Sustainable Chem. Eng., 2016, 4, 3368-3378.

12 (a) O. Kotova, R. Daly, C. M. G. dos Santos, M. Boese, P. E. Kruger, J. J. Boland and T. Gunnlaugsson, Angew. 
Chem., Int. Ed., 2012, 51, 7208-7212; (b) J. Q. Pan, L. P. Guo, S. Q. Zhang, N. Wang, S. B. Jin and B. E Tan, Chem.-Asian J., 2018, 13, 1674-1677.

13 K. W. Wang, L. M. Yang, X. Wang, L. P. Guo, G. Cheng, C. Zhang, S. B. Jin, B. E. Tan and A. Cooper, Angew. Chem., Int. Ed., 2017, 56, 14149-14153.

14 Y. Z. Liao, J. Weber, B. M. Mills, Z. H. Ren and C. F. J. Faul, Macromolecules, 2016, 49, 6322-6333.

15 S. Q. Li, X. D. Zhang and Y. M. Huang, J. Hazard. Mater., 2017, 321, 711-719.

16 (a) S. Lagergren, K. Sven. Vetenskapsakad. Handl., 1898, 24, 139; (b) Y. S. Ho and G. McKay, Process Biochem., 1999, 34, 451-465; (c) S. X. Duan, R. F. Tang, Z. C. Xue, X. X. Zhang, Y. Y. Zhao, W. Zhang, J. H. Zhang, B. Q. Wang, S. Y. Zeng and D. Z. Sun, Colloids Surf., A, 2015, 469, 211-223.
17 Z. Hasan, J. Jeon and S. H. Jhung, J. Hazard. Mater., 2012, 209-210, 151-157.

18 (a) I. Langmuir, J. Am. Chem. Soc., 1918, 40, 1361-1403; (b) H. Freundlich and W. Heller, J. Am. Chem. Soc., 1939, 61, 2228-2230.

19 J. Dong, F. F. Xu, Z. J. Dong, Y. S. Zhao, Y. Yan, H. Jin and Y. X. Li, RSC Adv., 2018, 8, 19075-19084.

20 X. M. Peng, F. P. Hu, F. L. Y. Lam, Y. J. Wang, Z. M. Liu and H. L. Dai, J. Colloid Interface Sci., 2015, 460, 349-360.

21 (a) H. Zhao, X. Liu, Z. Cao, Y. Zhan, X. D. Shi, Y. Yang, J. L. Zhou and J. Xu, J. Hazard. Mater., 2016, 310, 235-245; (b) J. Ma, M. X. Yang, F. Yu and J. Zheng, Sci. Rep., 2015, 5, 13578, DOI: 10.1038/srep13578. 